\title{
Study on Control Strategy for Regenerative Braking in a Pure Electric Vehicle
}

\author{
Kun $\mathrm{Ma}^{1, \mathrm{a}}$, Liang $\mathrm{Chu}^{1}$, Liang $\mathrm{Yao}^{1}$, Yanbo Wang ${ }^{1}$ \\ ${ }^{1}$ State Key Laboratory of Automobile Simulation and Control, Jilin University, Changchun, China \\ aEmail:makun2014@126.com
}

Keywords: Pure electric vehicle, Regenerative braking, Energy-saving rate, Vehicle verification

\begin{abstract}
Regenerative braking is one of the important ways to extend the driving mileage of pure electric vehicle. Through analyzing the brake regulations and the vehicle dynamics, a control strategy was proposed to solve the problem on braking force distribution for the pure electric vehicle. The rate of regenerative braking ${ }^{[1]}$, the rate of energy-saving and the rate of extended driving mileage were served as evaluating indexes of the control strategy. Finally the simulation was carried out by MATLAB/simulink and AVL-Cruise under different profiles. The control strategy was also validated by vehicle experiment. The results show that the strategy can distribute the brake forces rightly and recover relatively more energy.
\end{abstract}

\section{Introduction}

With the increasing shortage of petroleum, new energy vehicle has become an important theme in the auto industry ${ }^{[2]}$. Regenerative braking is one of major technologies to save energy and reduce emission for hybrid electric vehicle, pure electric vehicle and fuel-cell electric vehicle. This paper put forward a regenerative braking control strategy which can distribute the force under braking regulations .At last the strategy was validated by simulation and vehicle experiment.

\section{Design of regenerative braking strategy}

According to the automobile theory, the following definitions (1) and (2) were given ${ }^{[3]}$ :

$\varphi_{\mathrm{f}}=\frac{\beta \mathrm{z}}{\frac{1}{\mathrm{~L}}(\mathrm{~b}+\mathrm{zh} \mathrm{g})}$

$\varphi_{\mathrm{r}}=\frac{(1-\beta) \mathrm{z}}{\frac{1}{\mathrm{~L}}(\mathrm{a}-\mathrm{zh} \mathrm{g})}$

Where:

$\varphi_{\mathrm{f}}$-Front axle utilized road friction coefficient

$\varphi_{\mathrm{r}}$ - Rear axle utilized road friction coefficient

$\beta$-Braking force distribution coefficient

z-Severity of braking

L-Wheel base

a-Distance between center of gravity and front axle

$\mathrm{b}$-Distance between center of gravity and rear axle

$\mathrm{h}_{\mathrm{g}}$ - Height of center of gravity

Based on the ECE regulations, the following inequality (3) was derived:

$\left\{\begin{array}{c}\varphi_{\mathrm{f}}>\varphi_{\mathrm{r}} \\ \mathrm{z} \geq 0.1+0.85\left(\varphi_{\mathrm{f}}-0.2\right) \\ \mathrm{z} \geq 0.1+0.85\left(\varphi_{\mathrm{r}}-0.2\right)\end{array}\right.$

After calculating the inequalities by MATLAB, the relation curve between braking force distribution rate $(\beta)$ and severity of braking $(\mathrm{z})$ can be received, as figure. 1 shows. From figure. 1 we can come to a conclusion that when $\mathrm{z}<0.13$, front axle is permitted to generate the whole vehicle brake force. At the same time, the demands of regulations are always fulfilled by making $\beta=$ 0.7. So the strategy of braking force distribution is shown in figure. 2 . 
In figure.2, the horizontal axis is for the total brake force of front axle and the vertical axis is for the total braking force of rear axle, and the following observations can be obtained:

(1) When $\mathrm{z}<0.13$, braking force distribution rate $\beta$ is equal to 1 . As the adhesion coefficient of ice-snow road is $0.15 \sim 0.25$, the front wheel will not be locked at this time and the vehicle stability will also be maintained. If possible all of the front axle braking force will be supplied by motor;

(2) When $0.13<\mathrm{z}<0.2$, the increase of the front axle braking force will break the regulation, so the rear axle braking force will increase with the front axle force remaining unchanged;

(3) When $0.2<\mathrm{z}<0.81$, to guarantee the consistency of driver braking feel and the demand of brake regulations, the braking force distribution rate $\beta$ is set to 0.7 ;

(4) When $\mathrm{z}>0.81$, the wheel has great possibility to be locked. Considering the vehicle safety, the regenerative braking will quit ${ }^{[4]}$. If ABS works, the actual braking force distribution curve will go along the ideal braking force distribution curve.

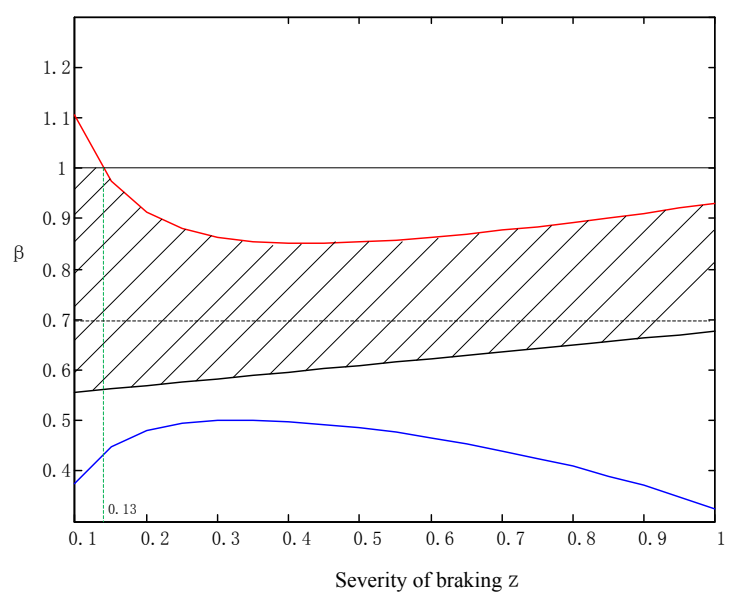

Figure.1 Demand of regulation

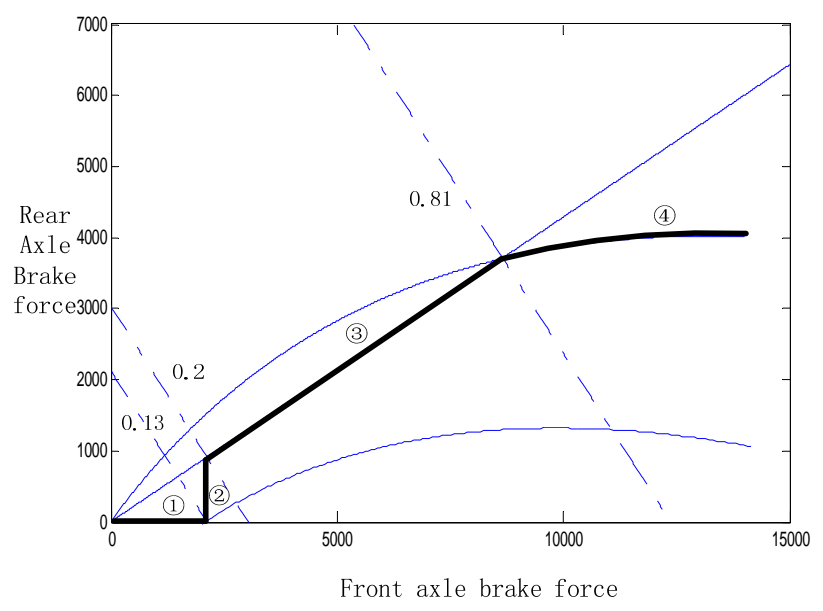

Figure.2 Brake force distribution The process diagram of the strategy was shown in figure. 3 .

\section{Simulation}

Evaluating index. In order to evaluate the amount of recovered energy, this paper verified the strategy by three evaluating indexes, namely rate of regenerative braking, rate of energy-saving and rate of extended driving mileage.

Where:

Rate of regenerative braking is derived from energy recovered by battery divided by brake kinetic energy

Rate of energy-saving is derived from energy recovered by battery divided by dissipated energy

Rate of extended driving mileage is derived from the difference between mileage with regenerative brake and mileage without regenerative brake, divided by mileage without regenerative brake.

Simulation result. The model was simulated on MATLAB/Simulink and AVL-Cruise ${ }^{[5]}$. Part of the simulation parameters can be seen in table 1. In the simulation, three profiles: NEDC, Jap-1015 and Jap-08 were used. The result was shown in table 2. 


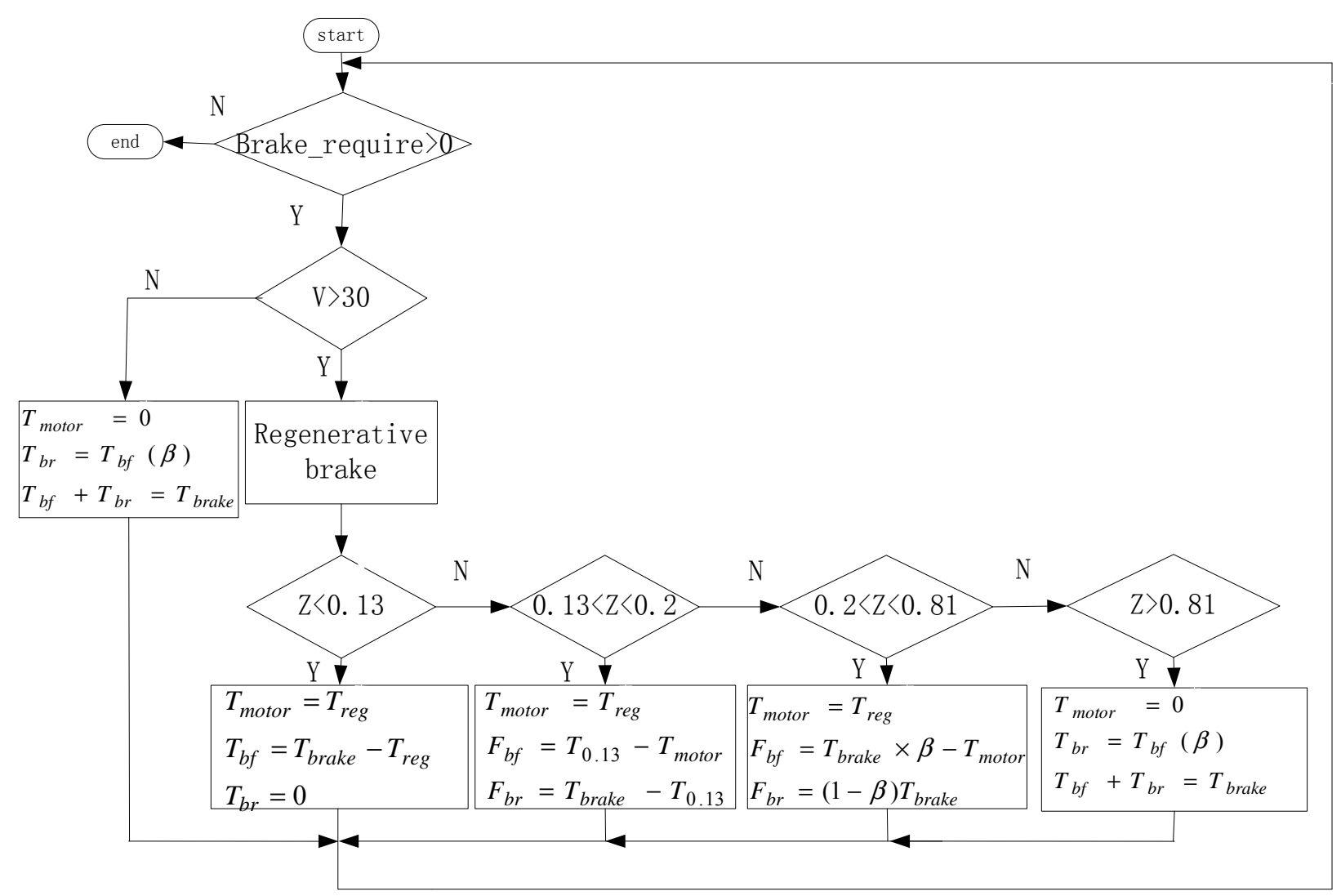

Figure.3 Process diagram of the strategy

Table 1 Part of the simulation parameters

\begin{tabular}{|c|c|}
\hline parameter & value \\
\hline Curb weight $[\mathrm{M} / \mathrm{kg}]$ & 1554 \\
\hline Rolling resistance coefficient & 0.01 \\
\hline Frontal area $\left[\mathrm{m}^{2}\right]$ & 1.98 \\
\hline Drag coefficient & 0.30 \\
\hline Air density $\left[\mathrm{kg} / \mathrm{m}^{3}\right]$ & 1.23 \\
\hline Correction coefficient of rotating mass & 1.03 \\
\hline
\end{tabular}

Table 2 Simulation result

\begin{tabular}{|c|c|c|c|}
\hline profile & Jap-1015 & Jap-08 & NEDC \\
\hline index & $62.69 \%$ & $62.96 \%$ & $56.33 \%$ \\
\hline Rate of regenerative braking & $49.20 \%$ & $46.99 \%$ & $21.04 \%$ \\
\hline Rate of energy-saving & $59.30 \%$ & $31.64 \%$ & $16.84 \%$ \\
\hline Rate of extended driving mileage & 18374 & 19465 & 12998 \\
\hline Energy recovered by battery[KJ] & 29309 & 30916 & 23073 \\
\hline Brake kinetic energy[KJ] & 37346 & 41425 & 61775 \\
\hline Energy dissipated & 94.89023 & 86.97827 & 115.11859 \\
\hline Mileage with regenerative brake[km] & 59.5670 & 66.07283 & 98.53022 \\
\hline
\end{tabular}

According to the simulation result, the amount of regenerative braking recovered energy is related to the profile. However the strategy proposed in this paper can reach satisfactory indexes in every single profile. 
The strategy was put into an electric car which didn't have regenerative braking strategy. The car was tested on the chassis dynamometer. The tested profile was NEDC. The result was in figure 4, figure 5 and table 3.

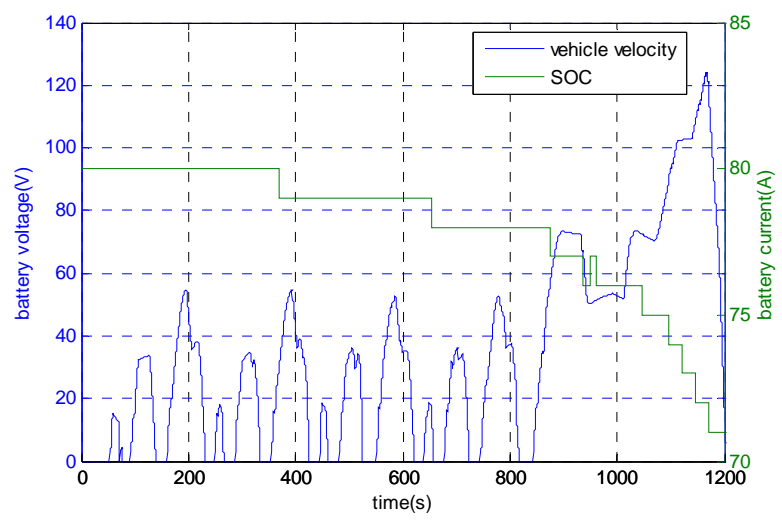

Figure.4 Vehicle velocity and SOC

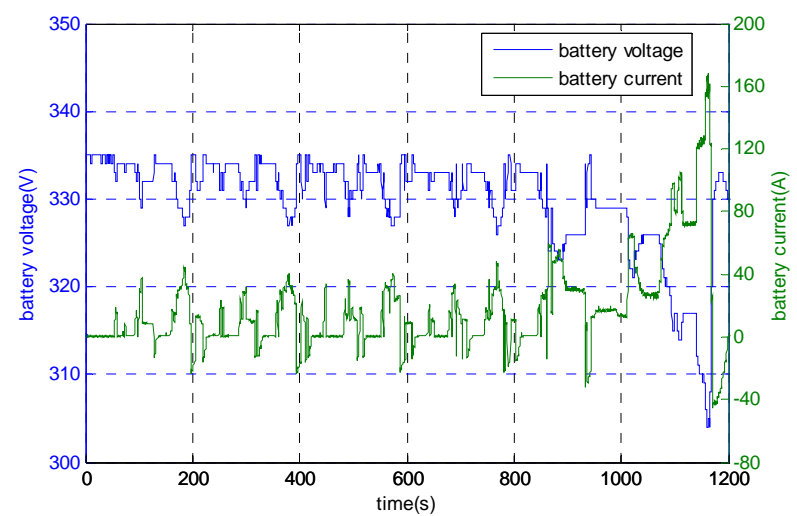

Figure.5 Battery voltage and current

Table 3 Vehicle verification result

\begin{tabular}{|c|c|c|c|}
\hline Index & $\begin{array}{c}\text { Rate of regenerative } \\
\text { braking }\end{array}$ & Rate of energy-saving & $\begin{array}{c}\text { Rate of extend driving } \\
\text { mileage }\end{array}$ \\
\hline value & $41.60 \%$ & $10.62 \%$ & $8.31 \%$ \\
\hline
\end{tabular}

According to the result, in vehicle test the strategy can still realize the function of regenerative braking.

\section{Conclusion}

This paper puts forward a control strategy for regenerative braking. The strategy is validated by software simulation and vehicle test. The combined simulation platform is based on MATLAB/Simulink and AVL-Cruise. The vehicle test is implemented on the chassis dynamometer. Three evaluating indexes are used to evaluate the energy-saving effect of the proposed strategy, which are the rate of regenerative braking, the rate of energy-saving and the rate of extended driving mileage. The results show that the strategy is feasible and can get satisfactory indexes.

\section{Acknowledgment}

Supported by Project 2010DFB70360 of Program of International S\&T Cooperation and Project 20121092 Graduate Innovation Fund of Jilin University

\section{References}

[1]Guofei LI, Yi LIN, Hongwen HE: Transactions of Beijing Institute of Technology Vol.29(2009),p.523

[2]M.Ehsani, Y.Gao, S.E.Gay, and A.Emadi, Modern electric, hybrid Electric, and fuel cell vehicles fundamentals, theory and design, CRC Press LLC, 2005.

[3]Zhisheng YU: Automobile Theory [M].Beijing: China Machine Press.2006

[4]Peng LI, Yunshan ZHOU and Nan WANG: Computer Simulation Vol.28 (2011), p.363

[5]Gaogao SHANG, Changjie OU, Qingyun SUN: Vehicle \& Power Technology Vol.126(2012),p.30 